\title{
Sintering of the Immersion-Induced Porous Stainless Steel Hollow Fiber Membranes
}

\author{
Haixia Li, Jian Song and Xiaoyao Tan*
}

State Key Laboratory of Separation Membranes and Membrane Processes, Department of Chemical Engineering, Tianjin Polytechnic University, Tianjin 300387, China

\begin{abstract}
Porous stainless steel (PSS) hollow fiber membranes have been fabricated by an immersion induced phase inversion and sintering technique. This paper is mainly focused on the sintering process. The influences of the sintering atmosphere as well as the sintering temperature and dwelling time on the microstructure, mechanical strength, and the permeation properties of the hollow fiber have been extensively investigated. Experimental results indicate that a $\mathrm{H}_{2}$-containing sintering atmosphere favors the formation of highly permeable porous PSS membranes with desirable mechanical strength. But the sintering atmosphere with $\mathrm{H}_{2}$ concentration larger than $25 \%$ is not necessary as it yields a marginal improvement on the membrane performances. For a sufficient sintering, the sintering temperature should be controlled between 1050 and $1100^{\circ} \mathrm{C}$, which ensures not only a desirable mechanical strength but also good membrane porosity. For cost effective and less time consuming, sintering time can be controlled within two hours. The resultant PSS hollow fibers satisfy the longstanding criteria of porous supports for gas separation membranes in terms of high porosity, high fluid permeance and robustness to withstand stress.
\end{abstract}

Keywords: Porous stainless steel membrane; Hollow fiber; Phase inversion; Sintering

\section{Introduction}

Inorganic membranes possess the advantages of high thermal stability, good chemical resistance and high mechanical strength, and thus have been targeted by a variety of advanced applications at high temperatures or environments involving corrosive chemicals $[1,2]$. Among them, the porous ceramic membranes have been broadly applied for many years but they generally exhibit some drawbacks such as brittleness and low thermal shock resistance. In contrast, porous metal membranes often made from stainless steel have high mechanical strength, offer good thermal shock resistance and allow for easy integration by welding or brazing in membrane module assembly, and therefore have been extensively used as the porous support to deposit other thin separation films such as Pd, silica and zeolites [3-9].

Most inorganic membranes in applications are usually designed into a planar or tubular configuration. Comparatively, the hollow fiber geometry is more favorable for practical use because it can provide a much higher surface-area-to-volume ratio. In the past decade, a combined phase inversion/sintering technique has been developed to fabricate various ceramic hollow fiber membranes [10-13]. Compared to other methods to produce inorganic hollow fibers, the phase inversion induced hollow fiber membranes also exhibit very significant advantages over the planar or tubular ones such as low permeation resistance due to the resultant asymmetric microstructures and low fabrication costs. Furthermore, the phase inversion/sintering technique is very versatile and can be modified to synthesize porous stainless steel (PSS) hollow fiber membranes [14-17].

So far the limited several studies on the preparation of PSS hollow fiber membranes by the phase inversion/sintering technique are mainly focused on the microstructure formation of the PSS hollow fibers during the phase inversion process. For example, Luiten-Olieman and co-workers reported the variation trend of the PSS hollow fiber microstructures with the spinning conditions and the composition of the spinning suspension [14-16]. We also reported the synthesis of the PSS hollow fiber membranes in spiral configurations by adding special additives in the spinning solution [18]. But the hollow fibers have low gas permeability due to the low surface porosity despite their apparent porosities are larger than $40 \%$, indicating the majority of pore volume was closed inside the fiber wall. Actually, the membrane properties like microstructure, surface porosity, pore size distribution and mechanical strength that should be critically considered in practical applications are significantly affected by the sintering conditions in the preparation of inorganic membranes [19]. For example, sintering of the PSS hollow fibres under air, $\mathrm{CO}_{2}, \mathrm{He}$ and $\mathrm{H}_{2}$ atmospheres would lead to different microstructures [20]. However, the general evolution of microstructure and performance of the resultant PSS hollow fibers with the variation of sintering conditions has not been much clarified.

The objective of this work was to elucidate the effects of sintering parameters including atmosphere, temperature and dwelling time on the microstructure and properties of the PSS hollow fibers spun by the phase inversion-sintering technique, and to identify the optimal sintering conditions at which high performance PSS hollow fiber membranes can be achieved.

\section{Experimental}

\section{Spinning of the PSS hollow fiber precursors}

The PSS hollow fiber precursors were spun from a dope mixture via the phase inversion process described in more details elsewhere $[10,11]$. For preparation of the spinning dope, stainless steel powder (AISI 316L, Fe/Cr18/Ni10/Mo3, mean particle size $=3 \mu \mathrm{m}$, purchased

*Corresponding authors: Xiaoyao Tan, State Key Laboratory of Separation Membranes and Membrane Processes, Department of Chemical Engineering, Tianjin Polytechnic University, Tianjin 300387, China, Tel: (86) 22-83955663, E-mail: tanxiaoyao@tjpu.edu.cn

Received October 18, 2015; Accepted November 12, 2015; Published November 14,2015

Citation: Li H, Song J, Tan X (2015) Sintering of the Immersion-Induced Porous Stainless Steel Hollow Fiber Membranes. J Membra Sci Technol 5: 136. doi:10.4172/2155-9589.1000136

Copyright: (c) $2015 \mathrm{Li} \mathrm{H}$, et al. This is an open-access article distributed under the terms of the Creative Commons Attribution License, which permits unrestricted use, distribution, and reproduction in any medium, provided the original author and source are credited. 
from Good Fellow Cambridge Limited) and organic additives were added into N-methylpyrrolidone (NMP, AR Grade, $>99.8 \%$, Kermel Chem Inc, Tianjin, China) solution followed by stirring for $30 \mathrm{~min}$. Polysulfone (PSf, Udel35000, Solvay USA) was then added in three steps, each separated by $2 \mathrm{~h}$. The mixture was stirred for $36 \mathrm{~h}$ untill all the polymer was completely dissolved to form a uniform suspension. The contents of PSf, NMP, 316L steel powder and organic additives in the spinning solution were $6.2,26.8,65.4$, and $1.6 \mathrm{wt} \%$, respectively. Prior to spinning, the suspension was degassed by applying vacuum for $1 \mathrm{~h}$ and left overnight under dry air. The spinning solution was extruded by a syringe pump through a tube-in-orifice spinneret (inner and outer diameter of $1.5 / 3.0 \mathrm{~mm}$, respectively) into a tap water bath for coagulation. Deionized water as the internal coagulant was pumped

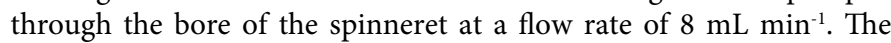
PSS hollow fiber precursors were kept in a water bath for $24 \mathrm{~h}$ for the thorough removal of NMP solvent.

\section{Sintering of the membranes}

Thermal treatment of the hollow fiber membranes was performed in a tubular furnace (GSL-1700X, Hefei Kejin Materials Tech. Co., China). Prior to sintering, the hollow fiber precursor was cut into short pieces of around $20 \mathrm{~cm}$ in length and dried in air for $48 \mathrm{~h}$. The hollow fiber precursors were firstly heated with the heating rate of $5^{\circ} \mathrm{C} \mathrm{min}-1$ to $600^{\circ} \mathrm{C}$ and calcined in static air at this temperature for $60 \mathrm{~min}$ to remove the polymer binder and the organic additives. Subsequent sintering was performed in static air or $\mathrm{H}_{2}-\mathrm{N}_{2}$ streams with different hydrogen concentrations, while the temperature was further elevated at a heating rate of $3^{\circ} \mathrm{C} \mathrm{min}{ }^{-1}$ to $1000 \sim 1200^{\circ} \mathrm{C}$, dwelling for 30,60 , 120 or $240 \mathrm{~min}$, respectively. The sintering process ended by cooling down to room temperature at $3^{\circ} \mathrm{C} \mathrm{min}{ }^{-1}$ under the same atmosphere. For each sintering condition, five hollow fiber samples were prepared for characterization and performance test. The average values over the samples were taken to evaluate the sintering effects on the hollow fiber properties.

\section{Characterization}

Scanning electron microscope (SEM, JEOL JSM 5600 LV) was used to examine the morphology and the microstructures of the hollow fiber membranes sintered under different conditions. SEM images were taken on both the cross-section and surface of the fibers. X-ray diffraction (XRD) patterns of the PSS hollow fibers were recorded with a Bruker D8 Advance diffractometer using $\mathrm{Cu} K a$ radiation $(\lambda=$ $0.15404 \mathrm{~nm}$ ). The hollow fibers were ground into fine powders prior to the XRD measurement. Continuous scan mode was used to collect $2 \theta$ data from $10^{\circ}$ to $80^{\circ}$ with a $0.02^{\circ}$ sampling pitch and a scan rate of $2^{\circ} \mathrm{min}^{-1}$. The X-ray tube voltage and current were set at $40 \mathrm{kV}$ and 30 $\mathrm{mA}$, respectively.

The pore size distribution of hollow fibers was measured using a mercury porosimeter (Micromeritics, Auto Pore IV 9500) employing mercury pressures between 1.50 and 33000 psi. Prior to measurement, the samples were heat-treated at $200^{\circ} \mathrm{C}$ for $2 \mathrm{~h}$ to remove adsorbed vapor. The weight of each sample for the measurements was around $1.2 \mathrm{~g}$. The evacuation and the equilibrating time were $5 \mathrm{~min}$ and 10 s, respectively. In addition, the porosity of the hollow fibers was also calculated from the bulk density estimated by the weight and the corresponding dimensions of the samples.

The mechanical strength of the hollow fibers was measured with a three-point bending instrument (Instron Model 5544) with a crosshead speed of $0.5 \mathrm{~mm} \mathrm{~min}^{-1}$ [21]. Hollow fiber samples were fixed on the sample holder with a distance of $4 \mathrm{~cm}$. The bending strength, $\sigma_{F}$, was calculated from the following equation:

$$
\sigma_{F}=\frac{8 F L D}{\pi\left(D^{4}-d^{4}\right)}
$$

Where $F$ is the measured force at which fracture takes place; $L, D$ and $d$ are the length $(4 \mathrm{~cm})$, the outer diameter and the inner diameter of the hollow fibers, respectively. The values of outer diameter $(D)$ and inner diameter $(d)$ were obtained from the SEM micrographs.

The permeation properties of the PSS hollow fiber membranes were evaluated by the nitrogen and pure water permeation measured in a dead-end mode under constant flux operation. The modules were custom-made by gluing a single fiber into glass tubing with an organic sealant [22]. Three different flux settings were used for each sample. The permeate flow was recorded as a function of the trans-membrane pressure. The pressure drop over the fiber is assumed to be negligible. The gas or water permeance through the hollow fiber was calculated by,

$$
P=\frac{N_{p}}{A_{m} \Delta p}
$$

Where $N_{p}$ is the molar flow rate of the permeate gas or water, $A_{m}$ the effective membrane area calculated by $A_{m}=\frac{\pi(D-d) L}{\ln (D / d)}$, and $\Delta p$ is the pressure difference across the membrane.

\section{Results and Discussion}

In order to obtain pure stainless steel membranes, the organics in the PSS hollow fiber precursors should be removed completely while the stainless steel phase is retained well. The burnout of organics is highly dependent on the composition of organics and the microstructure of precursor, thus much related to the gaseous atmosphere surrounding the precursor. A major concern of the sintering atmosphere is the presence of oxygen as it is required to burn out the organics, but on the other hand it should be used as less as possible to avoid the possible oxidation of iron phase. Thus, in this work, air was used at lower temperature of $600^{\circ} \mathrm{C}$ to burn out the organics in the hollow fiber precursor, after which inert or reducing gases were introduced to protect the stainless steel hollow fiber during the subsequent high temperature treatment to achieve the desired density and mechanical strength. Figure 1 shows the morphology of the hollow fiber precursor and the fiber sintered at $600^{\circ} \mathrm{C}$ for $1 \mathrm{~h}$. It can be seen that short fingerlike structures have been formed near both the outer and inner walls of the fiber, while a sponge-like structure occurs at the center of the fiber precursor (Figure 1a). This is the special feature of the hollow fiber membranes prepared by phase inversion method using water as both the external and the internal coagulants as the rapid precipitation occurred at both the inner and outer walls close to coagulants resulting in short finger pores but the slow precipitation at the center of the fiber giving the sponge-like structure $[10,11]$. The stainless steel particles are well dispersed and embedded inside polymeric matrix, as displayed in Figure 1a. After sintering at $600^{\circ} \mathrm{C}$ for $1 \mathrm{~h}$, the cross-sectional structure of the fiber precursor has been well preserved, as shown in Figure 1(b). The surface SEM image shows the absence of organic binders as they were removed completely during the sintering process (Figure $1 \mathrm{~b}$ ). The stainless steel particles keep their original spherical shape with particle size of around 1-3 microns, indicating sintering has not occurred yet at this temperature.

In order obtain the sintered PSS hollow fiber membranes with 
Citation: Li H, Song J, Tan X (2015) Sintering of the Immersion-Induced Porous Stainless Steel Hollow Fiber Membranes. J Membra Sci Technol 5: 136. doi:10.4172/2155-9589.1000136

Page 3 of 6

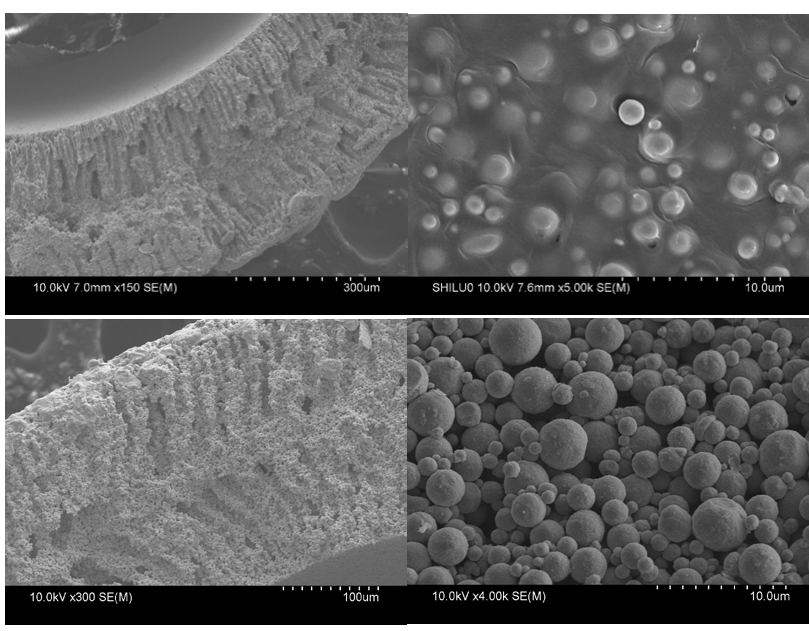

Figure 1: SEM images of the PSS hollow fiber precursor $(A, a)$ and the hollow fiber after removal of organics by sintering at $600^{\circ} \mathrm{C}$ for $1 \mathrm{~h}(\mathrm{~B}, \mathrm{~b})$. (A, B) for cross sectional; (a, b) for inner surface

certain mechanical strength, the sintering temperature was raised to $1050^{\circ} \mathrm{C}$ at heating rate of $5^{\circ} \mathrm{C} \mathrm{min}^{-1}$ and dwelling for 2 hours, under different atmospheres with flowing air, nitrogen and hydrogencontaining streams. Figure 2 compares the morphology of the resultant PSS hollow fibers. The general porous structure can be observed in all the sintered samples from the cross sectional areas, but the sandwiched structure is more perfectly preserved when using hydrogen-containing atmosphere although the quantity and the size of the pores have greatly decreased after the sintering process. The significant effect of the sintering atmosphere can be seen more clearly from the inner surface morphologies. For the fiber sintered in air, the inner surface looks quite dense with a few pores in the size of 1-2 microns randomly distributed. The formation of such dense surface structure may be due to the iron oxidation on the surface layer. Compared to metal iron, the formed iron oxides of $\mathrm{Fe}_{2} \mathrm{O}_{3}$ or $\mathrm{Fe}_{3} \mathrm{O}_{4}$ would increase the weight by $40 \%$, thus causing the volume swelling and making the surface denser. The formation of iron oxides can be confirmed by the XRD pattern that will be discussed later. For the sample sintered in nitrogen atmosphere, the surface also looks dense but the number of open pores is more than that of the fiber sample sintered in air. The possible reason for this phenomenon is still related to the volume and weight increase caused by the formation of iron nitride formed during the high temperature sintering stage or other impurities like iron oxides or carbonized compounds [23], which also can be evidenced by the $\mathrm{XRD}$ results below. However, when $\mathrm{H}_{2}$-containing atmosphere was applied, the resultant hollow fibers have shown a completely different surface morphology. The stainless steel particles retained their original spherical shape, and connected with each other to form a large quantity of micro pores. Sintering does not occur as deeply as in the air and nitrogen atmospheres, because hydrogen as the most effective reducing atmosphere allows for enhanced oxide removal, which necessitates longer sintering times. Furthermore, the small hydrogen atoms may diffuse into the metal lattice, leading to a puffy structure on the particle surfaces and inhibiting the elimination of final porosity, as shown in the Figure 2 [24]. Nevertheless, the dependence of the porosity with the $\mathrm{H}_{2}$ partial pressure in the sintering atmosphere cannot be easily perceived just from the SEM image alone. Other characterization techniques are required to better evaluate the effects of the hydrogen concentration in sintering atmosphere on the properties of the PSS hollow fiber membranes.

Figure 3 shows the XRD patterns of the PSS hollow fiber membranes sintered at $1050^{\circ} \mathrm{C}$ under different atmospheres, where the XRD pattern of the original stainless steel powders is also presented for comparison. As can be seen, the dominate phase in the original powder is martensite phase $(\alpha-\mathrm{Fe})$ identified at $44.50^{\circ}$ and $64.76^{\circ}$, but a minor amount of austenite phase $(\gamma-\mathrm{Fe})$ is also present identified by the characteristic peaks of $43.54^{\circ}, 50.70^{\circ}$ and $75.8^{\circ}$. After the stainless steel powder is formed into hollow fibers via sintering, the predominant phase will transform from martensite to austenite. Furthermore, the intensity of the characteristic peaks of all the hollow fibers has been reduced significantly. This can be attributed to the re-crystallization effect, i.e., the large grains were broken up into smaller ones during the high-temperature sintering process [25]. Some additional peaks are also identified in the XRD patterns of the hollow fibers, indicating that some impurity phases have been generated after sintering. Types of the impurity phases are highly dependent on the sintering atmosphere. For example, carbon compounds such as $\mathrm{Mo}_{12} \mathrm{Fe}_{22} \mathrm{C}_{10}$ (PDF card code

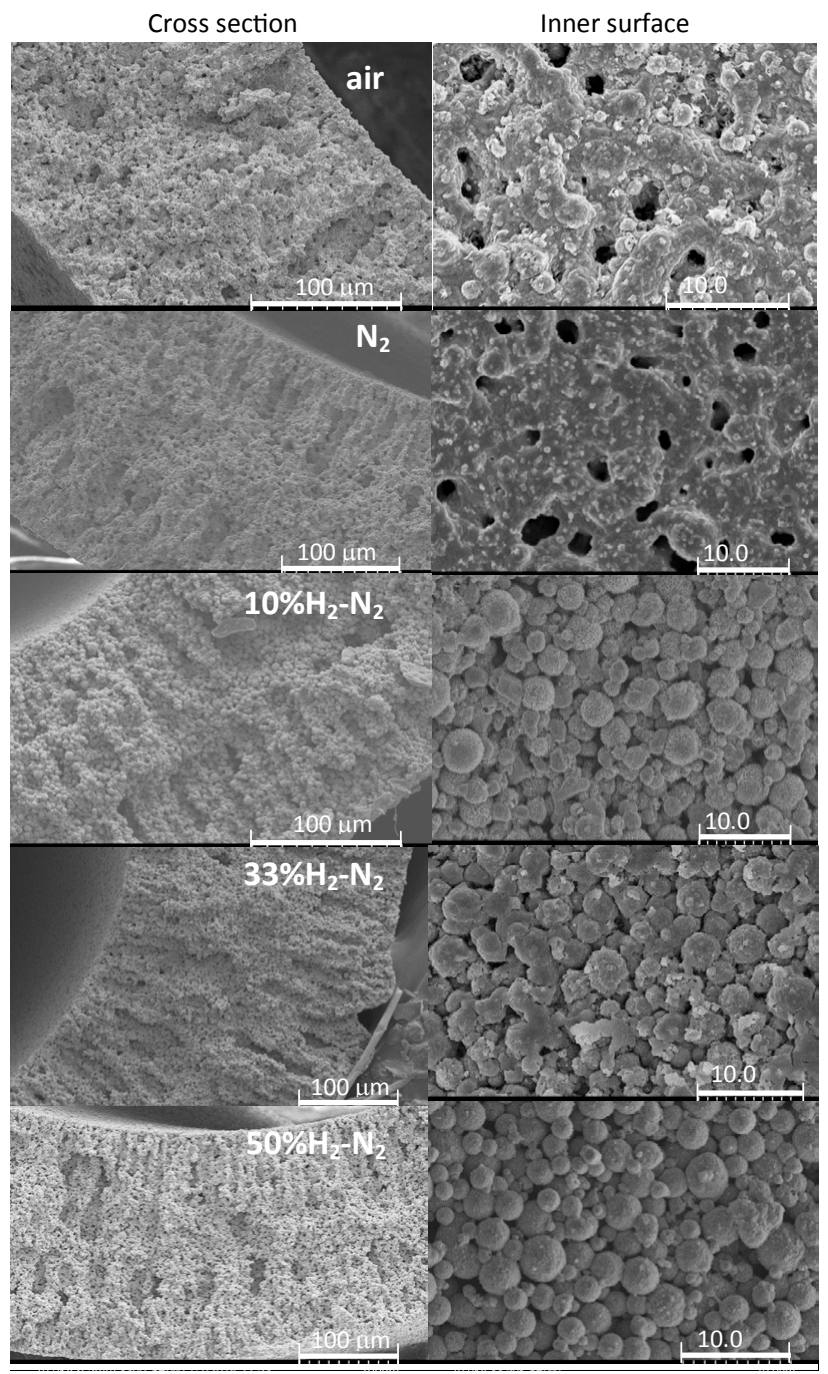

Figure 2: SEM images of the cross sectional and inner surface of the PSS hollow fiber membranes sintered at $1050^{\circ} \mathrm{C}$ for $2 \mathrm{~h}$ in different sintering atmosphere. 


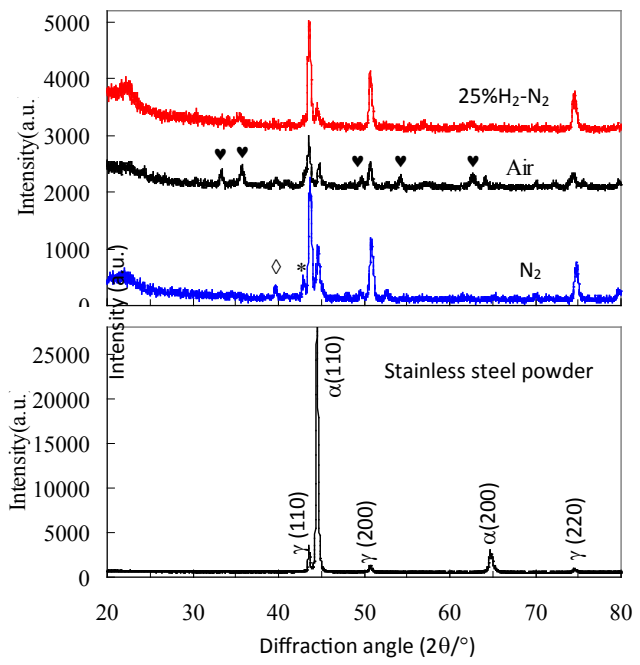

Figure 3: XRD patterns of the original stainless steel powder and the PSS hollow fiber membranes sintered at $1050^{\circ} \mathrm{C}$ under different atmospheres (impurity phases: $* \mathrm{Mo}_{12} \mathrm{Fe}_{22} \mathrm{C}_{10} ; \diamond \mathrm{Mo}_{2} \mathrm{C} ; \bullet \mathrm{Fe}_{2} \mathrm{O}_{3}$ ).
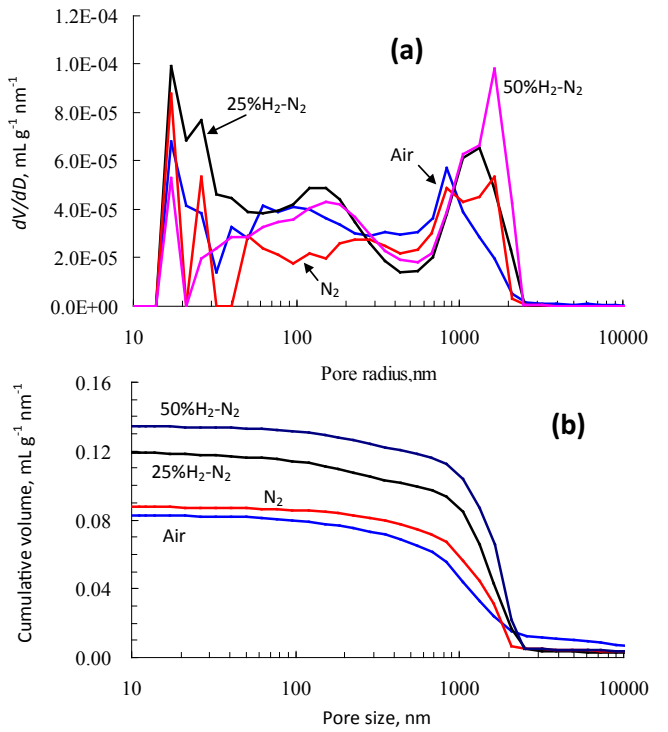

Figure 4: Pore size distribution (a) and cumulative volume (b) of the PSS hollow fiber membranes sintered under different atmospheres.

78-0272) and $\mathrm{Mo}_{2} \mathrm{C}$ (PDF card code 77-0720) were detected in the $\mathrm{N}_{2}$-sintered hollow fibers, whereas the main impurity would be $\mathrm{Fe}_{2} \mathrm{O}_{3}$ in the hollow fibers sintered in the air atmosphere. Under the $\mathrm{H}_{2}-$ containing reducing atmosphere, the impurities would no longer be observed in the XRD pattern. In the presence of hydrogen, any iron oxides like $\mathrm{Fe}_{2} \mathrm{O}_{3}$ could be reduced to metal phase, and the formation of iron compounds would be inhibited.

Figure 4 describes the pore size distribution of the hollow fibers sintered at $1050^{\circ} \mathrm{C}$ under different sintering atmospheres. Despite the atmosphere difference, all the fiber samples exhibit a bimodal pore size distribution (Figure 4a) with the pores ranging from 0.01 to $3 \mu \mathrm{m}$. This is a typical feature of the asymmetric membranes fabricated by the phase inversion method $[26,27]$. Figure $4 \mathrm{~b}$ shows the cumulative pore volume distribution, from which it is clear that the majority of porosity is contributed from the pores of 1-3 microns. The pore volume alternation is highly related to the sintering atmosphere. At the same sintering temperature, the sintering atmosphere with larger $\mathrm{H}_{2}$ partial pressure confers the sample with a larger volume; on the other hand, the sample sintered in oxidant (air) environment possesses the smallest volume. This result is consistent with the observation from the SEM images, and also agrees with the literature report [24]. It suggests that, to be applied as the substrate for supported thin membrane synthesis for fluid separation, the PSS hollow fibers should be sintered in the atmosphere with $\mathrm{H}_{2}$ since a more porous structure is preferred to minimize the transport resistance through the substrate. Furthermore, although the fibers sintered in the $50 \% \mathrm{H}_{2}-\mathrm{N}_{2}$ atmosphere possess the largest pore volume, the $25 \% \mathrm{H}_{2}-\mathrm{N}_{2}$ atmosphere is more preferably recommended since the resultant fibers have the most micro pores smaller than $0.2 \mu \mathrm{m}$ while those sintered in the $50 \% \mathrm{H}_{2}-\mathrm{N}_{2}$ atmosphere mainly possess the macro pores between $1 \sim 3 \mu \mathrm{m}$ in diameter. In order to further recognize the role of hydrogen in sintering, the effect of hydrogen concentration in the sintering atmosphere on the porosity, mechanical strength and permeances of both nitrogen and pure water have been investigated and presented below.

Figure 5 plots the porosity and mechanical strength of the prepared PSS hollow fibers against the $\mathrm{H}_{2}$ concentration in the sintering atmosphere. As displayed, the general trend of porosity change with the $\mathrm{H}_{2}$ concentration is increasing, which is opposite to the change of mechanical strength. This is a reasonable observation as a higher porosity generally signals a lower mechanical strength. However, as consistently observed, the change of the porosity and mechanical strength with further $\mathrm{H}_{2}$ concentration increment is very marginal after the $\mathrm{H}_{2}$ concentration reached up to $25 \%$. In this case, a higher $\mathrm{H}_{2}$ concentration than $25 \%$ in the sintering atmosphere is not very necessary as it will increase the operational cost related to the safety issues during the sintering operation.

Figure 6 displays the $\mathrm{N}_{2}$ and water permeance of the sintered membranes versus the $\mathrm{H}_{2}$ content in the sintering atmosphere, where the sintering temperature and the dwelling time were fixed at $1050^{\circ} \mathrm{C}$ and $2 \mathrm{~h}$, respectively. As expected, both the nitrogen and water permeance increases with increasing the hydrogen concentration in the sintering atmosphere, since the presence of hydrogen induces more porosity especially on the hollow fiber surfaces. For example, when sintered in nitrogen atmosphere, the hollow fiber exhibited a nitrogen permeance of $1.77 \times 10^{-4} \mathrm{~mol} \mathrm{~m}^{-2} \mathrm{~s}^{-1} \mathrm{~Pa}^{-1}$, which is of the same order of magnitude as reported in the literature [16]. As the hydrogen content in the sintering

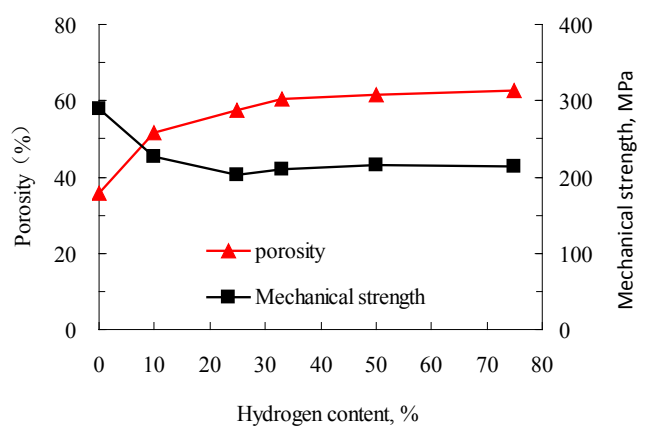

Figure 5: Effect of hydrogen content in the $\mathrm{H}_{2}-\mathrm{N}_{2}$ sintering atmosphere on the porosity and mechanical strength of the PSS hollow fibers sintered at $1050^{\circ} \mathrm{C}$ for $2 \mathrm{~h}$ 


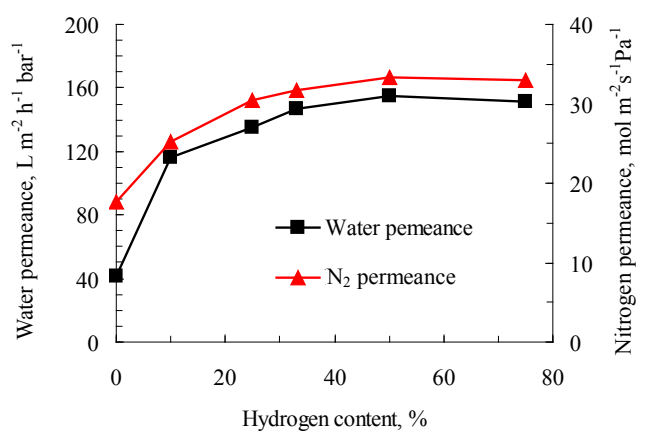

Figure 6: Plots of nitrogen and pure water permeances of the PSS hollow fibers sintered at $1050^{\circ} \mathrm{C}$ for $2 \mathrm{~h}$ against the hydrogen content in the $\mathrm{H}_{2}-\mathrm{N}_{2}$ sintering atmosphere.

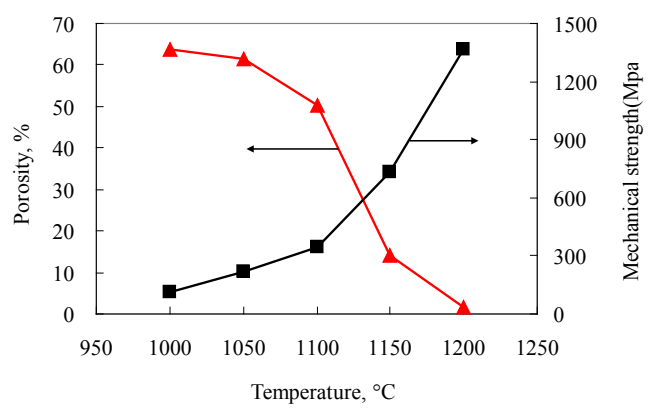

Figure 7: Effect of sintering temperature on the porosity and mechanical strength of the PSS hollow fiber membranes sintered under the $25 \% \mathrm{H}_{2}$ containing atmosphere.

stream was increased to $10 \%$ and $25 \%$, the nitrogen permeance would increase by $42.8 \%$ and $72.6 \%$ to $2.52 \times 10^{-4}$ and $3.05 \times 10^{-4} \mathrm{~mol} \mathrm{~m}^{-2} \mathrm{~s}^{-1} \mathrm{~Pa}^{-1}$, respectively. These values for the permeance mean that the fibers are suitable as porous support structures for gas separation membranes. Likewise, the water permeance increased significantly from $41.6 \mathrm{~L} \mathrm{~m}^{-2}$ $\mathrm{h}^{-1} \mathrm{bar}^{-1}$ for fiber sintered in the nitrogen atmosphere to 115.2 (2.79 times) and 135.4 (3.25 times) $\mathrm{L} \mathrm{m}^{-2} \mathrm{~h}^{-1}$ bar $^{-1}$ for the fibers sintered in the $10 \% \mathrm{H}_{2}-\mathrm{N}_{2}$ and $25 \% \mathrm{H}_{2}-\mathrm{N}_{2}$ sintering atmospheres, respectively. Again, the permeation results also indicate that the higher hydrogen concentration than $25 \%$ in the sintering atmosphere would yield a limited increase in both the nitrogen and water permeance, thus is not necessary for sake of safety and operational cost.

For the $\mathrm{H}_{2}$-containing atmosphere $\left(25 \% \mathrm{H}_{2}\right)$, other sintering parameters such as the sintering temperature and dwelling time have also been investigated with the results presented in Figures 7-9. Figure 7 illustrates the porosity and mechanical strength of the PSS hollow fibers sintered at different temperatures with a fixed dwelling time of $2 \mathrm{~h}$. In general, there is a trade-off between the porosity or pemeance and the mechanical strength. That is, a larger porosity often mirrors the better performance in fluid permeance but suffers a lower mechanical strength due to the insufficient bonding at lower temperature. An important indication from this figure is that the sintering temperature should not be higher than $1100^{\circ} \mathrm{C}$ otherwise the porosity would decrease remarkably from $50.3 \%$ to $14.1 \%$, although the mechanical strength has also improved significantly. This implies that the permeation properties of the PSS hollow fibers would be deteriorated noticeably as the sintering temperature increases. As shown in Figure 8, the water permeance decreased significantly from $155.0 \mathrm{~L} \mathrm{~m}^{-2} \mathrm{~h}^{-1}$ bar $^{-1}$ to $38.3 \mathrm{~L}$ $\mathrm{m}^{-2} \mathrm{~h}^{-1}$ bar $^{-1}$, and then to $2.2 \mathrm{~L} \mathrm{~m}^{-2} \mathrm{~h}^{-1}$ bar $^{-1}$ as the sintering temperature was increased from $1050^{\circ} \mathrm{C}$ to $1100^{\circ} \mathrm{C}$ and $1150^{\circ} \mathrm{C}$, respectively. Further increment of the sintering temperature to $1200^{\circ} \mathrm{C}$ will transfer the hollow fiber into a dense structure, for which no gas permeation could not be detected any more.

Figure 9 shows the porosity and mechanical strength of the PSS hollow fibers sintered at $1050^{\circ} \mathrm{C}$ under the $25 \% \mathrm{H}_{2}$-containing atmosphere as a function of sintering time. It can be seen that the porosity decreased from $65.1 \%$ to $61.7 \%$, while the mechanical strength increased noticeably from 107.9 $\mathrm{MPa}$ to $210.9 \mathrm{MPa}$ as the sintering time was extended from $30 \mathrm{~min}$ to $90 \mathrm{~min}$, but further extension of the sintering time would hardly change the mechanical strength and the porosity any more. This implies that the fusion and bonding of the stainless particles mainly occurred within the initial 90 min duration. In order to guarantee the complete sintering, two hours of sintering time is sufficient for economical purpose.

\section{Conclusions}

Porous stainless steel (PSS) hollow fibers with asymmetric structure have been developed through the immersion-induced phase inversion and sintering technique. The sintering atmosphere has significant influence on the microstructure and properties of the resultant hollow fiber membranes. Experimental results indicate that $\mathrm{H}_{2}$-containing atmosphere for sintering can lead to the formation of highly permeable

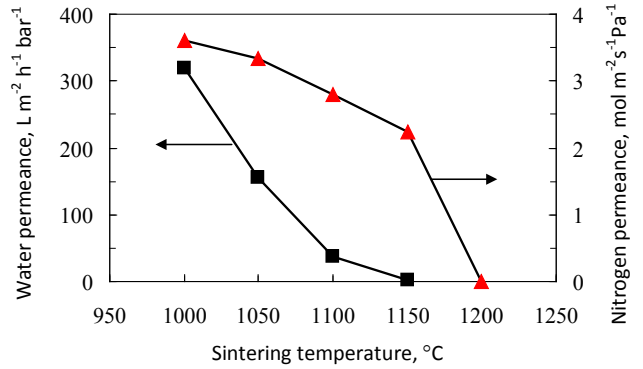

Figure 8: Nitrogen and pure water permeance of the PSS hollow fiber membranes sintered at different temperatures under the $25 \% \mathrm{H}_{2}$-containing atmosphere.

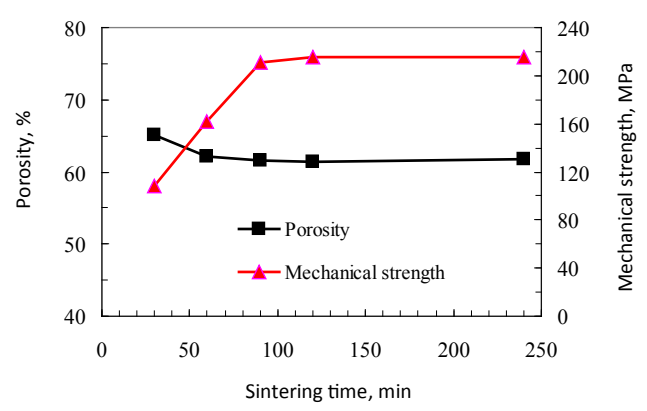

Figure 9: Effect of sintering time on the porosity, mechanical strength of the PSS hollow fiber membranes sintered under the $25 \% \mathrm{H}_{2}$-containing atmosphere. 
Citation: Li H, Song J, Tan X (2015) Sintering of the Immersion-Induced Porous Stainless Steel Hollow Fiber Membranes. J Membra Sci Technol 5: 136. doi:10.4172/2155-9589.1000136

porous membranes with desirable mechanical strength, but the $\mathrm{H}_{2}$ concentration in the sintering atmosphere higher than $25 \%$ in nitrogen is not necessary as it yields a limited improvement on the membrane performances. For a sufficient sintering, the sintering temperature should be higher than $1050^{\circ} \mathrm{C}$ so as to yield a desirable mechanical strength, but not higher than $1100^{\circ} \mathrm{C}$, otherwise the porosity will be decreased noticeably due to densification. For cost effective and less time consuming, sintering time can be controlled within two hours. The resultant PSS hollow fibers possess the advantages of high porosity, high fluid permeance, robustness to be handled with stress, thereby in addition to be directly applied for microfiltration, they are also suitable to be used as porous supports for next step thin membrane synthesis for gas separations or desalinations.

\section{Acknowledgements}

The authors gratefully acknowledge the research funding provided by the National Natural Science Foundation of China (NSFC 21176187), the Research Fund for the Doctoral Program of Higher Education of China (RFDP 20131201110007) and the Program for Changjiang Scholars and Innovative Research Team in University (PCSIRT) of Ministry of Education of China (IRT 13084)

\section{References}

1. Burggraaf AJ, Cot $L$ (1996) Fundamentals of Inorganic Membrane Science and Technology. Elsevier Science B.V, The Netherlands.

2. Julbe A, Farrusseng D,Guizard C (2001) Porous ceramic membranes for catalytic reactors - overview and new ideas. Journal of Membrane Science 18 : 3-20.

3. Liang W, Hughes R (2005) The catalytic dehydrogenation of isobutane to isobutene in a palladium/silver composite membrane reactor. Catalysis Today, 104: 238-243.

4. She Y, Han J, Ma YH (2001) Palladium membrane reactor for the dehydrogenation of ethylbenzene to styrene. Catalysis Today 67: 43-53.

5. Lin WH, Chang HF (2004) A study of ethanol dehydrogenation reaction in a palladium membrane reactor. Catalysis Today 97: 181-188.

6. Bernal MP, Coronas J, Menendez M, Santamaria J (2002) Coupling of reaction and separation at the microscopic level: esterification processes in a H-ZSM-5 membrane reactor. Chemical Engineering Science 57: 1557-1562.

7. Kong C, Lu J, Yang J, Wang J (2007) Catalytic dehydrogenation of ethylbenzene to styrene in a zeolite silicalite-1 membrane reactor. Journal of Membrane Science 306: 29-35.

8. Haag S, Hanebuth M, Mabande GTP, Avhale A, Schwieger W, et al. (2006) On the use of a catalytic $\mathrm{H}-\mathrm{ZSM}-5$ membrane for xylene isomerization. Microporous and Mesoporous Materials 96: 168-176.

9. Brands K, Uhlmann D, Smart S, Bram M, da Costa JCD (2010) Long-term flue gas exposure effects of silica membranes on porous steel substrate. Journal of Membrane Science 359: 110-114

10. Tan X, Liu S, Li K (2001) Preparation and characterization of inorganic hollow fiber membranes. Journal of Membrane Science 188: 87-95.

11. Tan X, Liu Y, Li K (2005) Preparation of La0.6Sr0.4Co0.2Fe0.8O3- $\delta$ hollow fiber membranes for oxygen production by a phase-inversion/sintering technique. Industrial and Engineering Chemistry Research 44: 61-66.

12. Meng B, Tan X, Meng X, Qiao S, Liu S (2009) Porous and dense Ni hollow fibre membranes. Journal of Alloys and Compounds 470: 461-464.

13. Luiten-Olieman MWJ, Raaijmakers MJT, Winnubst L, Bor TC, Wessling M et al. (2012) Towards a generic method for inorganic porous hollow fibers preparation with shrinkage-controlled small radial dimensions, applied to $\mathrm{Al} 2 \mathrm{O} 3, \mathrm{Ni}, \mathrm{SiC}$, stainless steel, and YSZ. Journal of Membrane Science 407408: $155-163$.
14. Luiten-Olieman MWJ, Winnubst L, Nijmeijer A, Wessling M, Benes NE (2011) Porous stainless steel hollow fiber membranes via dry-wet spinning. Journal of Membrane Science 370: 124-130.

15. Luiten-Olieman MWJ, Raaijmakers MJT, Winnubst L, Wessling M, Nijmeijer A et al. (2011) Porous stainless steel hollow fibers with shrinkage-controlled small radial dimensions. Scripta Materialia 65: 25-28.

16. Michielsen B, Chen H, Jacobs M, Middelkoop V, Mullens S, et al. (2013) Preparation of porous stainless steel hollow fibers by robotic fiber deposition. Journal of Membrane Science 437: 17-24.

17. Aran HC, Pacheco Benito S, Luiten-Olieman MWJ, Er S, Wessling M, et al. (2011) Carbon nanofibers in catalytic membrane microreactors. Journal of Membrane Science 381: 244-250.

18. Li H, Song J, Tan X, Jin Y, Liu S (2015) Preparation of spiral porous stainles steel hollow fiber membranes by a modified phase inversion-sintering technique. Journal of Membrane Science 489: 292-298.

19. K. Li (2007) Ceramic Membranes for Separation and Reaction. (1stedn), John Wiley and Sons Ltd, West Sussex, England.

20. Rui W, Zhang C, Cai C, Gu X (2015) Effects of sintering atmospheres on properties of stainless steel porous hollow fiber membranes. Journal of Membrane Science 489: 90-97.

21. Yang $N$, Tan $X$, Ma $Z$ (2008) A phase inversion/sintering process to fabricate nickel/yttria-stabilized zirconia hollow fibers as the anode support for microtubular solid oxide fuel cells. Journal of Power Sources 183: 14-19.

22. Tan X, Liu Y, Li K (2005) Mixed conducting ceramic hollow fiber membranes for air separation. AIChE Journal 51: 1991-2000.

23. Kurgan N (2013) Effects of sintering atmosphere on microstructure and mechanical property of sintered powder metallurgy $316 \mathrm{~L}$ stainless steel. Materials \& Design 52 995-998

24. Dudek A, Włodarczyk R (2013) Effect of sintering atmosphere on properties of porous stainless steel for biomedical applications. Materials Science and Engineering C 33: 434-439.

25. Umm-i-K, Bashir S, Ali N, Akram M, Mahmood K, et al. (2012) Effect of ambient environment on excimer laser induced micro and nano-structuring of stainless steel. Applied Surface Science 261: 101-109.

26. Kingsbury BFK, Wu Z, Li K (2010) A morphological study of ceramic hollow fibre membranes: A perspective on multifunctional catalytic membrane reactors. Catalysis Today 156: 306-315.

27. Kingsbury BFK, Li K (2009) A morphological study of ceramic hollow fibre membranes. Journal of Membrane Science 328: 134-140. 